\title{
Treatment of the ischemic hand in frostbite by revascularization with interpositional vein graft and digital palmar sympathectomy: A case report
}

\author{
Achilleas Thoma MD FRCSC FACS, Jaggi Rao BSc, H Alexander Heggtveit MD FRCP DABP FCAP FRCPC \\ Department of Surgery, Division of Plastic and Reconstructive Surgery, St Joseph's Hospital and \\ Department of Pathology, McMaster University Medical Centre, McMaster University, Hamilton, \\ Ontario
}

\begin{abstract}
A Thoma, J Rao, HA Heggtveit. Treatment of the ischemic hand in frostbite by revascularization with interpositional vein graft and digital palmar sympathectomy: A case report. Can J Plast Surg 1999;7(4):195-198.

In severely ischemic hands where the microcirculation is not amenable to reconstruction, there is evidence that palmar digital sympathectomy has salutary effects. This report describes the case of a patient with a painful, ulcerated, ischemic hand secondary to ulnar artery stenosis, generalized vasospasm and intimal hypertrophy that resulted from cold injury. Surgical treatment involved an interpositional vein graft replacing a thrombotic segment of the ulnar artery and concomitant palmar digital sympathectomy. The coupling of these two microvascular procedures completely relieved the patient's symptoms, increased total blood flow and improved the vascular function of the hand. The combination of reconstruction of an occluded vessel with peripheral sympathectomy in treating difficult cases of ischemic hand injury is recommended.
\end{abstract}

Key Words: Frostbite; Hand; Ischemia; Palmar digital sympathectomy; Vein graft

Traitement de la main ischémique à la suite d'engelures par revascularisation avec interposition d'un greffon veineux et par sympathectomie digito-palmaire : un rapport de cas

RÉSUMÉ : Dans le cas d'une main sévèrement ischémique où la microcirculation ne peut être reconstruite, les preuves démontrent qu'une sympathectomie digito-palmaire a des effets salutaires. Le présent rapport décrit le cas d'un patient avec une main ischémique, ulcérée et douloureuse résultant d'une sténose de l'artère cubitale, d'un vasospasme généralisé et d'une hypertrophie de l'intima causée par les engelures. Le traitement chirurgical impliquait

l'interposition d'un greffon veineux visant à remplacer un segment thrombosé de l'artère cubitale et une sympathectomie digito-palmaire concomitante. Le couplage de ces deux techniques de chirurgie microvasculaire a complètement soulagé les symptômes du patient, augmenté le débit sanguin et amélioré la fonction vasculaire de la main. On recommande donc de combiner la reconstruction d'un vaisseau occlus à une sympathectomie périphérique pour traiter les cas difficiles de main ischémique.

\begin{abstract}
A 65-year-old man presented with pregangrenous fingertips of his left hand. The left index finger had ulcerated on the palmar tip, and the other fingers had a bluish discolouration (Figure 1). These ischemic changes were associated with pain, requiring analgesics.

The patient stated that his condition began approximately one year before presentation, while moose hunting in north-
\end{abstract}

Correspondence and reprints: Dr Achilleas Thoma, 200 James Street South, Suite 208, Hamilton, Ontario L8P 3A9. Telephone 905-523-0019, fax 905-523-0229, e-mail athoma@fhs.mcmaster.ca ern Ontario. On this expedition, his hands suffered severe frostbite, but he continued hunting despite recognizing the problem. He had suffered similar insults to his hands on previous yearly hunting trips, but to a lesser degree. The patient had a 53 pack-year smoking history but had stopped smoking soon after the consultation. He also had a long-standing history of hypertension. There was no history of diabetes, myocardial infarction or atrial fibrillation.

Clinically, Allen's test was positive, showing complete occlusion of the ulnar artery. Interestingly, although it was the ulnar artery that appeared occluded, the worse insult appeared to the index finger. 


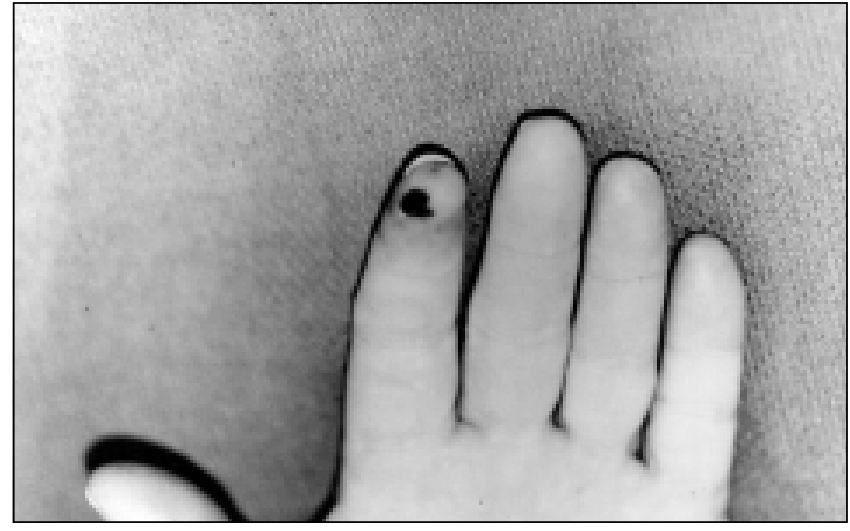

Figure 1) Pregangrenous fingertips of the left hand resulting from ischemic changes caused by cold injury. The index finger has ulcerated on the palmar tip and the other fingers show skin discolouration

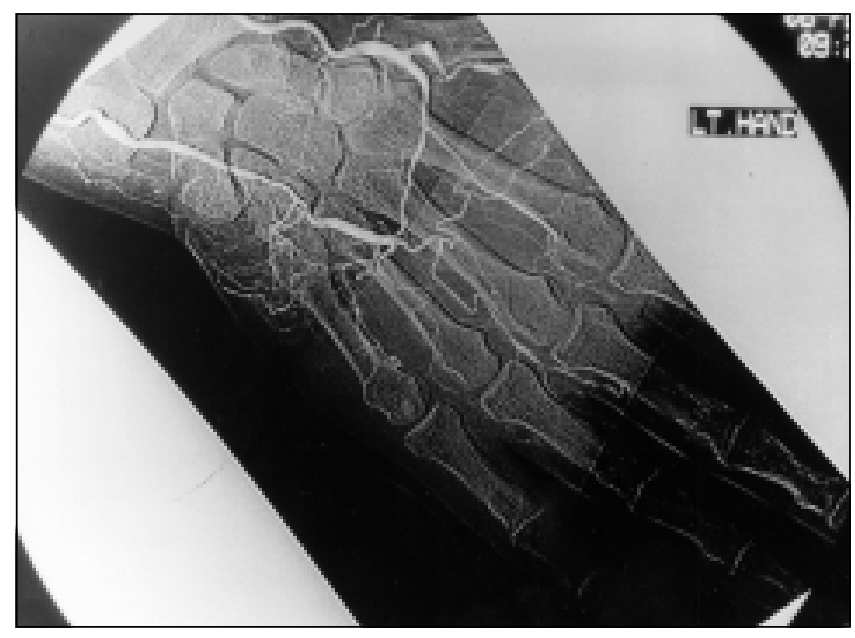

Figure 2) Angiogram showing occlusion of the ulnar artery of the left hand at the level of the hook of the hamate. The superficial palmar arch is hypoplastic and tortuous, and there is truncation of the digital arteries

An angiogram of the left hand showed a stenotic lesion of the ulnar artery at the level of the hook of the hamate. Radiology also revealed a hypoplastic superficial palmar arch with concomitant vessel tortuosity and truncation of the digital arteries (Figure 2). There was no response to the papaverine injection.

Before this consultation, the patient was seen by a vascular surgeon who prescribed acetylsalicylic acid (325 mg daily), vitamin E, pentoxifylline (400 $\mathrm{mg}$ tid) and amlondipine ( $5 \mathrm{mg}$ daily), all for a duration of three weeks. Upon completion of this regimen, the patient's pain did not subside and there was no improvement in the discolouration of his fingers. The vascular surgeon offered a very pessimistic prognosis to the patient, recommending amputation of the painful digits.

Surgery was performed by the senior author (Dr A Thoma) at St Joseph's Hospital, Hamilton, Ontario. The patient underwent resection of a $2 \mathrm{~cm}$ segment of completely thrombotic left ulnar artery, slightly distal to the level of the hamate (Figures 3,4). As flow from the ulnar artery was ex-

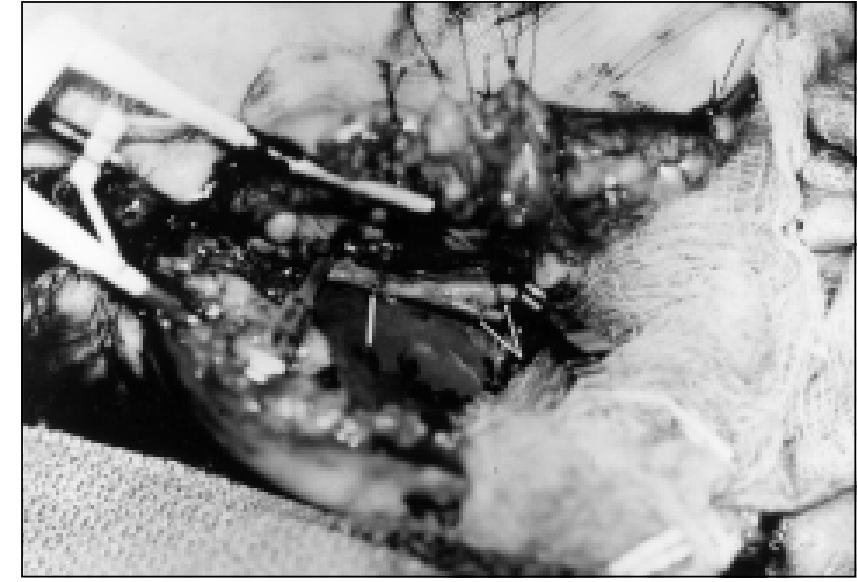

Figure 3) Intraoperative photograph showing anastomosis of a $Y$-shaped interpositional vein graft proximally to the left ulnar artery, and distally to the superficial palmar arch and common digital arteries of the ring and little fingers

tremely sluggish, a $2 \mathrm{~mm}$ catheter was inserted $20 \mathrm{~cm}$ proximally to dilate it and achieve pulsatile flow. The artery was resected distally until open lumen was identified in the superficial palmar arch. A $2 \mathrm{~cm}$ vein graft from the dorsum of the foot was then harvested in a Y-shaped proximal branching pattern, which allowed a proximal anastomosis to the ulnar artery. Distally, one of the limbs of the vein graft was anastomosed to the superficial palmar arch and the second to the common digital arteries of the ring and little fingers. The distal stumps of these vessels were diseased, with obvious hypertrophy of the vessel walls. Less than ideal lumen was found to perform the anastomosis. Because of the diffuse nature of the disease, further resection of the digital arteries was not necessary.

A palmar digital sympathectomy was also performed in which the adventitia from the common digital arteries in the palm were stripped to the level of the proper digital arteries in the web spaces. During the circumferential stripping of the adventitia, the vessels looked abnormal, having a tortuous appearance with hypertrophic walls.

The histological examination of the resected ulnar artery segment and superficial palmar arch showed patchy destruction of the internal elastic lamina along with marked fibroelastic intimal thickening and narrowing of the lumen (Figure 5). An inflammatory cell infiltrate was noted within the fibrointimal tissue that consisted of numerous eosinophils mixed with mononuclear inflammatory cells and fibrin. Microscopically, giant cells and other histological features of Beurger's disease were not present. Scattered hemosiderenladen macrophages were present in the vessel wall, suggesting previous hemorrhage. It is likely that this hemorrhage was related to the vasospasm that occurred during cold injury.

Postoperatively, Allen's test showed good perfusion to the hand via the reconstructed ulnar artery. In addition, Doppler pulses were obtained at the base of each digit, which were not possible preoperatively. The pain caused by ische- 


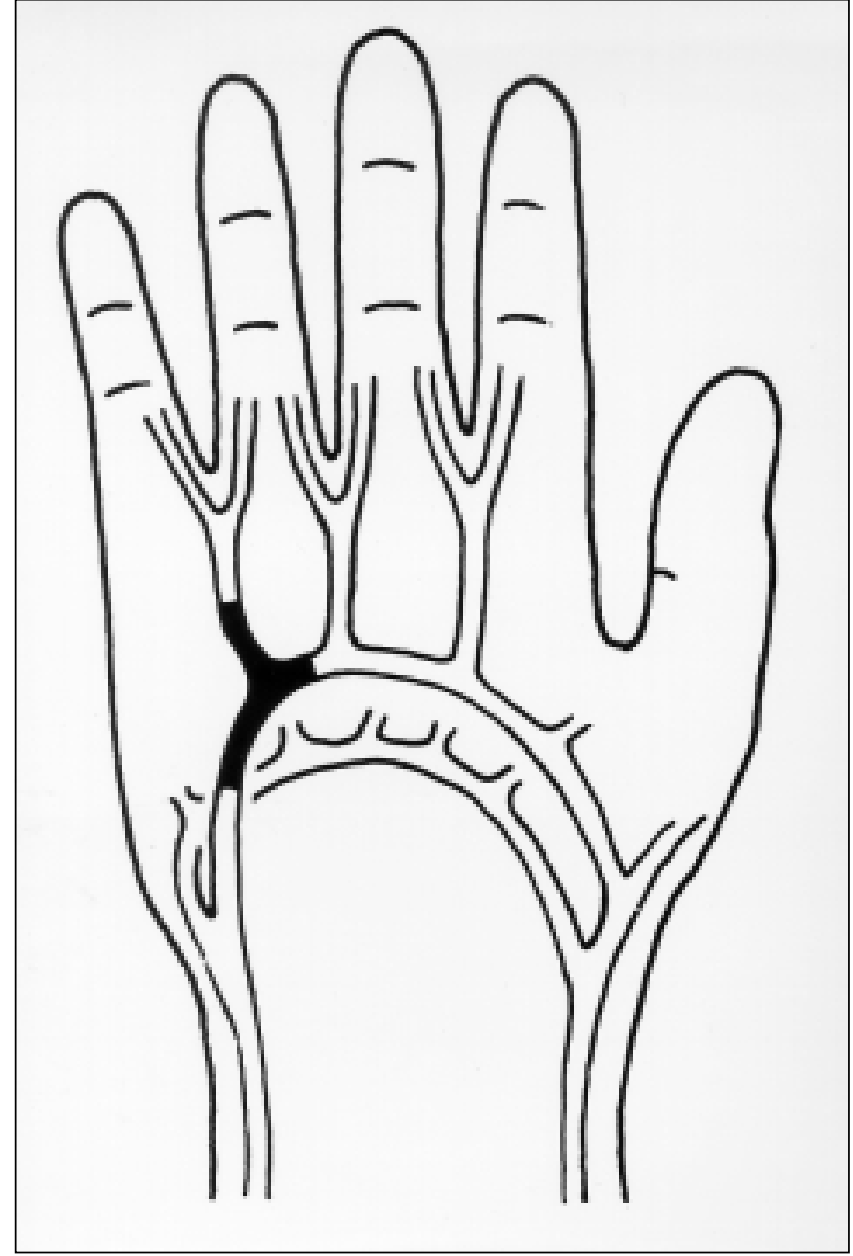

Figure 4) Diagram representing the site of the interpositional vein graft shown in Figure 3

mia disappeared immediately after the surgery, and the ulcer completely healed within three weeks (Figure 6). Since his last follow-up at over one year after surgery, the patient remains symptom-free, has returned to his job and is functioning as he did before his injury.

\section{DISCUSSION}

Frostbite occurs when skin and subcutaneous tissues are exposed to temperatures of less than $2^{\circ} \mathrm{C}$ for variable lengths of time (1). Frostbitten skin exhibits markedly dilated and blood-filled capillaries in the superficial dermis, which is often associated with edema. Depending on the severity and rapidity of the hypothermic insult, direct tissue injury, as well as vasoconstriction, may occur. Over time, this is associated with sludging, thrombosis and fibromuscular obliteration of the vascular lumen with duplication of vessel wall components such as the internal elastic lamina (2). The effect is stenosis and occlusion of blood vessels, resulting in ischemic necrosis of tissues.

In addition to the ischemic effects related to vascular pathology in frostbite patients, there is often neuromuscular injury causing other sequelae. Patients frequently develop cold

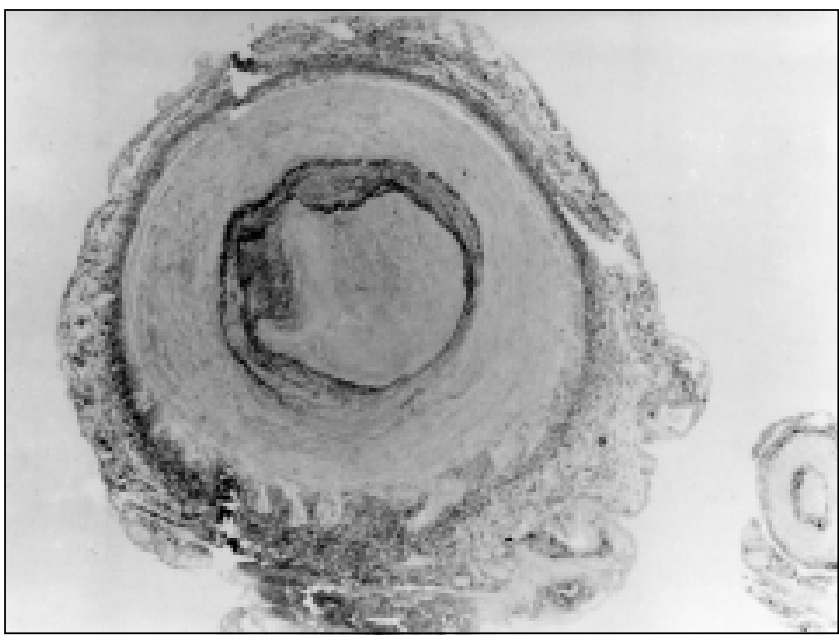

Figure 5) Cross section of the ulnar artery showing fibromuscular obliteration of the lumen with focal destruction and duplication of the internal elastic lamina. Elastic Van Gieson stain $\times 30$

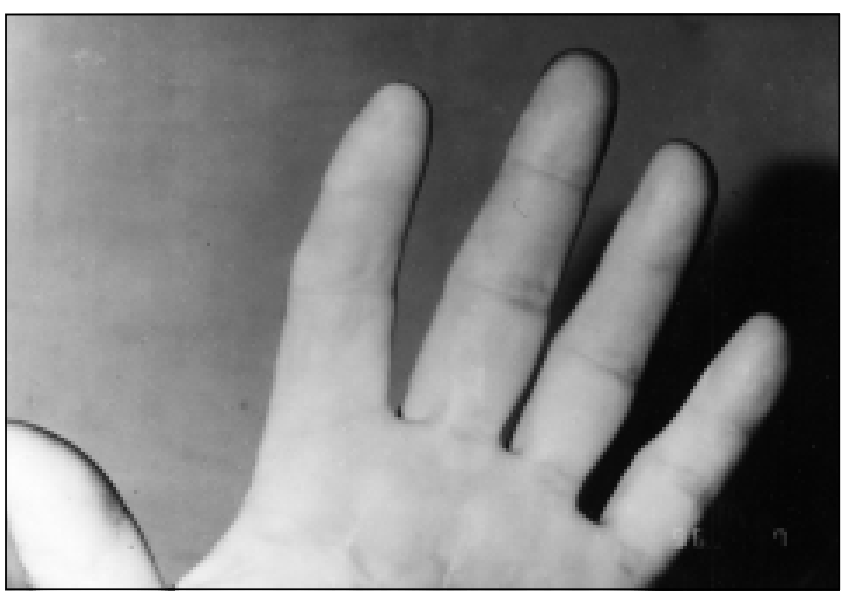

Figure 6) Five-month postoperative photograph of the patient's left hand following vascular reconstruction and peripheral sympathectomy. The ulcer on the tip of the index finger has completely healed, and the skin discolouration of the other fingertips has disappeared

sensitivity, hyperhidrosis and intrinsic muscle atrophy. The development of arthritis, hyperesthesias, chronic pain and vasospastic attacks is not uncommon. Vasospasm is particularly detrimental in ischemic injury because it promotes further stenosis of blood vessels, greatly increasing the risk of anoxia and tissue necrosis. Consequently, in frostbite, as with crush injury and some connective tissue disorders, the microcirculation is so widely affected by pathological changes that vascular reconstruction by itself is not adequate to treat the severe ischemia (2).

For over thirty years, cervicothoracic sympathectomy was common therapy if nonoperative management of chronic vasospastic digital symptoms failed. Some symptoms treated by sympathectomy included the Raynaud's phenomenon, hyperhidrosis in the hand and chronic hand pain, all with reasonable results. However, this procedure has provided only transient benefit, and long term results of sympathectomy performed in the proximal part of the upper limb are gener- 
ally discouraging. This may be attributed to incomplete denervation, regeneration of autonomic nerve fibres and activation of alternative pathways (3). It was also shown that sympathectomy is relatively more successful for hyperhidrosis than for the alleviation of vascular disease.

In 1980, Flatt (4) suggested the use of a distal interruption of the periarterial sympathetic fibers and digital nerve branches to the common and proper digital arteries to control symptoms of digital vascular insufficiency. This 'peripheral' sympathectomy has provided significant palliation to patients with frostbite, crush injuries, scleroderma and Raynaud's disease.

Autonomic innervation of blood vessels consists of sympathetic axons, which are located around the external perimeter of arteries. These fibres are contained only within the adventitia and do not penetrate the media. As such, peripheral sympathectomy is performed by isolating the terminal branches of the sympathetic nerves, dividing these branches and stripping the adventitia from the appropriate digital arteries. Care must be exerted when stripping adventitia so as not to perforate the digital artery (5).

Arterial occlusive disease induces a vasomotor disturbance that exacerbates ischemia and vasospasm downstream (6). The theoretical basis of peripheral sympathectomy is to reduce the release of norepinephrine at the myoneural junction in the vessel wall, thereby eliminating vasospasm and dilating arterial smooth muscle (7).

Peripheral sympathectomy has two major advantages over proximal cervicothoracic sympathectomy. First, it eliminates sympathetic fibres that bypass the sympathetic trunk. In addition, the effect has been shown to last longer and is often effective when central or cervicothoracic sympathectomy has failed $(5,7)$. The clinical improvement in pain and cold intolerance, and the healing of previously recalcitrant digital ulcers fol-

\section{REFERENCES}

1. Vogel JE, Dellon AL. Frostbite injuries of the hand. Clin Plast Surg 1989;16:565-76.

2. Bourne MH, Piepkorn MW, Clayton F, Leonard LG. Analysis of microvascular changes in frostbite injury. J Surg Res 1986;40:26-35.

3. Pick J. The Autonomic Nervous System. Philadelphia: JB Lippincott, 1970.

4. Flatt AE. Digital artery sympathectomy. J Hand Surg [Am] 1980;5:550-6.

5. Koman LA, Smith BP, Pollock FE Jr, Smith TL, Pollock D, Russell GB. The microcirculatory effects of peripheral sympathectomy. J Hand Surg [Am] 1995;20:709-17.

6. Leriche R, Fontaine R, Dupertuis SM. Arterectomy with follow-up on 78 operations. Surg Gynecol Obstet 1937;64:149-56. lowing this surgery are thought to be the result of improvement in nutritional microcirculatory flow (7).

In situations, such as ulnar artery thrombosis where there is adequate collateral circulation, excision and ligation of the thrombosed or diseased arterial segment may be effective to interrupt the vasomotor disturbance distally (6). If, however, collateral flow is inadequate, or if there are multiple levels of occlusion, re-establishing arterial inflow by reconstruction and restoration of the arterial anatomy is preferred (8). Even very long vein grafts with multiple branching to the palmar arch and common digital arteries are possible (9).

In the present case, frostbite-induced vascular change that is normally isolated to the microvasculature, was shown to involve a larger vessel, namely the ulnar artery. Reconstruction of the superficial palmar arch was performed using a reverse interposition vein graft with an end-to-end anastomosis to the distal ulnar artery and end-to-side anastomoses to the common digital arteries. This was done with the hope of increasing the inflow pressure to the digits and, thereby, improving the perfusion of the involved digits. The patient reported short term relief from acute digital pain, demonstrated healing of the ulcer, and no longer showed signs of Raynaud's disease, even after one year follow-up. This correlates well with peripherally sympathectomized patients described in the literature who have also shown reduction in the severity of cold intolerance $(5,7,10)$.

Reconstruction of an occluded vessel and peripheral sympathectomy have been shown to increase total blood flow, relieve symptoms and to improve hand function (11). Combining these two procedures in difficult to manage cases of severe cold-induced ischemic injury to the hand is recommended.
7. el-Gammal TA, Blair WF. Digital periarterial sympathectomy for ischaemic digital pain and ulcer. J Hand Surg [Br] 1991;16:382-5.

8. Troum SJ, Smith TL, Koman LA, Ruch DS. Management of vasospastic disorders of the hand. Clin Plast Surg 1997;24:121-32.

9. Thoma A, Ginty M. Spontaneous thrombosis of the ulnar artery from midforearm to common digital arteries. J Hand Surg [Am] 1992;17:211-3.

10. Jones NF. Ischemia of the hand in systemic disease. The potential role of microsurgical revascularization and digital sympathectomy. Clin Plast Surg 1989;16:547-56.

11. Egloff DV, Mifsud RP, Verdan CL. Superselective digital sympathectomy in Raynaud's phenomenon. The Hand 1982;15:110-4. 